\title{
Impact of Modern Processes in Management Education on the Acquired Competencies
}

\author{
Alina Sherstneva \\ Novosibirsk State University of Economics and Management, 630099 Novosibirsk, Russia
}

\begin{abstract}
The article discusses the conceptual issues of traditional and digital forms of study. This type of education has grown over the last few years and has experienced mainstream acceptance. The theoretical aspects of motivation refined and expanded by the results of practical research. Particularly the survey shows the most important aims of education for applicants. The article was aimed to find balance between different approaches. The main purpose is to evaluate how different approaches to economics and management education affect different sets of skills. Whether or not the educational initiatives affect students attitudes and career intentions, these are central concepts in our evaluation studies. The article presents advantages and obstacles for possible solution in educational process.
\end{abstract}

\section{Introduction}

The research interest in management started among economists who wanted to explain the function that management and innovations played in changing the economy. This was followed by an increased interest among behavioral scientists who focused on explaining which characteristics that separated managers from other individuals. The focus turned towards entrepreneurial processes, i.e. how managed to create new innovations, value and organizations.

It was mainly management scholars who entered the field at this time, which to some extent explains the contextual focus on small and new firms, as well as the popularity of teaching management methods such as business planning and market and competitor analysis. During the last decade this management-oriented process focus has been criticized by researchers who view leadership as a method and who propagate that rather than teaching students the discipline, we should teach them the toolbox that enables them to navigate the discipline.

Individuals can engage in uncertain activities and pursue opportunities in order to create new economic activity within established companies as well as governmental and civic organizations. Another management definition has a strong focus on new value creation. This phenomenon- and value creation-oriented definition of management naturally makes definition of management education fairly broad and inclusive. From the other side, in turn influences the type of assessment studies we perform and which type of variables that we focus on. Naturally, we have a focus on self-employment and new venture creation, since this is an important way to generate innovation and new value creation. 
At the lower levels of education, we also have a strong focus on school-related variables such as educational motivation, relationship with classmates and teachers, and school engagement. Since pupils at this level of education are far away from the labor market the validity of career-related variables is limited. This increases the importance of focusing on other factors that are important in the short run, but which are also associated with future labor market success.

In assessment studies it is also necessary to define cognitive-oriented management skills as skills which contain a high level of declarative knowledge. These types of skills are thus easy to codify and teach in educational settings. Business plan writing, assessing entrepreneurial opportunities and financial literacy are typical examples of cognitiveoriented management skills or "hard" skills. Non-cognitive skills, or soft skills contain a high level of tacit knowledge and require practice to be learned. Typical examples of management skills of a non-cognitive character are creativity, resource marshalling, ambiguity tolerance and sense of initiative. These types of skills have been viewed as unteachable traits, which are innate rather than fostered. Researchers have commonly categorized them as belonging to the art, rather than the science, of management, and thus, as a part of the entrepreneurial mindset rather that the management skillset [1-3].

\section{Problem statement}

The main interest has been to evaluate how different approaches to economics and management education affect different sets of skills. Whether or not the educational initiatives affect students attitudes and career intentions, these are central concepts in our evaluation studies.

All these results are aiming to achieve longer-term outcomes, promoting innovation and self-employment by development of students' personal attributes that create management mentality and ability. Engineering and ICT studies will introduce permanent tools into teaching methodologies and existing curricula aiming to support students' creativity and own initiative, willingness to take risks, their autonomy and self-confidence based on continuous individual benchmarking and built capacities on commercialization, market assessment and capital risk.

Such results will also enable raising students' awareness of potentials of selfemployment and entrepreneurship as a management career, offering also tailored knowledge on exploring business opportunities in engineering and ICT, start-up companies' foundation, business planning and successful management. Such change will make a good replication potential for other universities, within the same or other areas of studying. Survey expected impacts relate to the change of youngsters' attitude towards the management and leadership, resulting with increased jobs creation and thus local development.

\section{Materials and methods}

Open online courses have become extremely popular last days. Since the primary objective of educational institutions is to transfer knowledge and foster skills that are necessary in today's society and labor market, there are big number different platforms that offers courses with the same educational purposes. Using platforms for teaching has obvious advantages such as the ability to choose the right course in any educational institution. For people who already have education, they are considered as an opportunity to complement the existing set of knowledge and skills. For those who are interested in acquiring specific knowledge and do not aim at obtaining a diploma, such platforms simplify the process of 
acquiring knowledge, since they are specifically aimed at the course of study and do not require additional, sometimes unnecessary, courses to study.

More than 50 million learners worldwide are using video lectures for digital learning. Coursera and EdX are the giants in this market. In cooperation with universities and companies, Coursera offers various open online courses, specializations, degrees, professional and master track courses. These courses provide quizzes, weekly exercises, peer-graded and reviewed assignments, an optional honors assignment, and sometimes a final project or exam to complete the course. After successfully completing the course, students are able to receive a certificate and post it into the LinkedIn profile. Some of the courses provided on-demand that allows students to be flexible with time management and being insight into a given topic. EdX operates similarly to Coursera. There are free and paid course series. In addition, learners can use the credits of some courses towards a master's degree at one of the cooperating partner universities.

«Open Education» is one of the most famous Russian platforms for online learning. It was founded by the cooperation of the leading Russian universities such as MSU, HSE, $\mathrm{SPbU}$ with the support of the Ministry of Science and Higher Education of the Russian Federation.

Courses on this platform are available for free. Students who want to credit completed courses within their bachelor's or specialist's degree program have to complete exams with the identification of the identity and pay for their certificates. Open education is a national platform and it has its unique requirements. All courses are developed due to federal education standards. Moreover, each university presents only its strongest courses of the best professors. In addition, the procedures for evaluating learning outcomes are also taken into account as well as effectiveness and quality of education [4-7].

\section{Practical results}

The practical results from survey, which focuses on the effects of different approaches to education for management on university students presented below. The programs included in this study are all practice-based and have a strong focus on professional skills, nevertheless, they have very different effects on students. We have sourced these differences in effects to the pro programs' focus on two areas, both of which are central to learning: psychological ownership and prior contextual knowledge.

The focus of analyses is to assess to what degree these programs have affected the students' activities and self-efficacy and which types of students the two approaches are particularly suitable for.

The survey was conducted among bachelor and master students of Novosibirsk State University of Economics and Management and include questions about preferences in education, traditional form and digital platforms, the opportunities and disadvantages that affect the choice.

The great majority of respondents are believed that the process of education at university is as difficult as student allows it to be. Even the most difficult course can be overcome in case that student work on it properly. Participation on lectures, discussing the given problems and taking a note is a key to success.

The next point was about the aims of education. It's necessary to mention that the answers were closed connected with the direction of study and dependent from specialty. For sure, the choice of university affects the future. The biggest point here is that students are extremely interested in acquisition diploma that shows not only getting professional skills but also prestige and ranking of organization for future employer. 


\section{The most important aim of education}

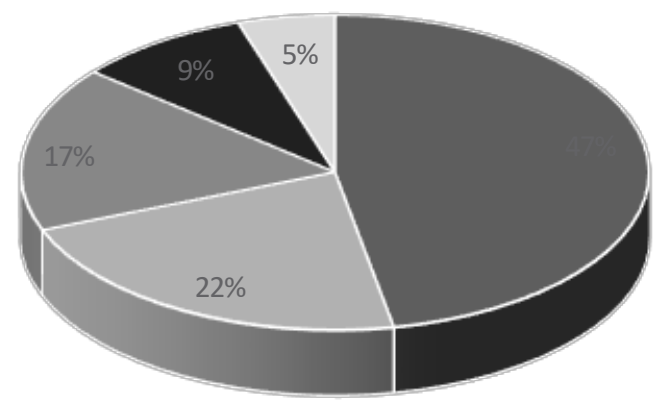

- To prepare for work environment

- To develop social skills

- To develop critical thinking

- To develop understanding of other people/ cultures

Others

Fig. 1. Educational aims.

Approximately $50 \%$ of respondents believes that the most important aim of education is to prepare students for work environment. High education gives the chance to study theoretical and methodological tools which allow to combine them and to create a new knowledge.

$17 \%$ and $22 \%$ respectively consider critical thinking and social skills as the most important in the modern world. Critical thinking is necessary in order to formulate correct conclusions and give an assessment of satiation. Hence the application of the results to various situations and problems.

$9 \%$ of students thinks that the most important thing in getting an education is a deeper understanding of other people. Through increasing awareness and learning about the processes within their, they can better understand themselves, the world around them, the people around, and be in a calmer and happier state.

On the basic of given information, the next question for respondent was about platforms of education.

When choosing a university, most of the students were guided by the ratings of the leading news agencies. The rating is based on: quality of education, quality of faculties, employment of graduates, number of publications and more. In Russia, several organizations such as RIA, «Forbes» magazine, Interfax and the Russian magazine «Finance» make ratings of Russian universities.

RIA and «Forbes» ratings are conducted by the Higher School of Economics. The ranking includes 476 universities and is based on the average USE score required for admission. RAEX became the first organization in Russia and the fourth in the world to be audited by the IREG Observatory. Interfax annually compiles a ranking of universities specializing in law. The Russian magazine «Finance» makes a rating of universities specializing in economics and finance. By choosing a university, applicants first of all assessed following indicators as quality of education, brand, research, socialization, internationalization, innovation. According to the common opinion this gave them confidence to make the right choice.

Part of respondents who is involved in practical issues with combination employment and study process note that some employers are ready to provide access to their own learning system.

For instance, Sber is the biggest company in Russia and is famous for its various digital platforms for clients and employees. Digital services embrace not only the education area, 
but they also cover other daily aspects. Every person in cities has an opportunity to order delivery of foodstuff from supermarkets, order taxis, pay for domestic services, and get access to online video and audio databases.

Sber has established its own virtual school to teach and train employees. In its library, there are 3.5 thousand electronic books and more than 1.5 thousand audio and video speeches of today's Russian and foreign authors, leaders, and business coaches. The database of the school is regularly updated. The specialists launched the online program for the development of self-management and anti-stress skills. In terms of the pandemic every person feels the over-stress, therefore this program aims to clarify its reasons and offers instruments for stress-reducing and body resilience increasing. For employees' convenience studying virtual school is available through smartphones at any time.

For instance, during the first pandemic wave, the distance study mode for school students has exposed weak points in platforms of the present education system. One more digital platform is «SberClass» for schools. This platform assistants to lead projects, to consolidate studied materials, to learn the favorite discipline. Currently digitalization level allows conveying the experience to other spheres of activity in Russia.

In terms of the pandemic, many companies have to put their stuff on distance working. For this moment, more than $50 \%$ of Sber employees are working at home, fully performing their working duties without health threat.

\section{Conclusion}

For students without previous entrepreneurship experience, it is important for their desire to become management that they are taught planning and financial understanding. It is important for students' entrepreneurial behavior that during teaching they feel they have ownership of the projects they are working with and that their earlier contextual experiences are involved.

People who have been trained/educated in management have a significantly higher income than those not educated in this sphere. The more training and teaching, the higher the income, even when we check other conditions such as gender, age, education and employment. Management and economics education encourage the desire and especially the skills needed for innovation and start-ups [7-9].

Overall, we should not deny the opportunities which online learning gives us. This type of education has grown over the last few years and has experienced mainstream acceptance.

Nowadays there is an unlimited number of courses that give the flexibility to organize schedule as people want. It allows to choose courses from the top-universities and participate in classes from any part of the world. It helps to develop a deeper understanding of the degree course. It also provides individuals an opportunity to finish a degree they might have started.

The biggest disadvantage of such approach is that online learning platforms leave students on their own and there are no professors who monitor the progress of studying.

The future of online degree education looks promising and opens up education to a larger section of the population than ever before. A solution can be founded in set of organizational tools such as online and offline education. Right mixture of educational institutional with combination of electronic approaches for interaction allows to remove all the shortcomings of the techniques.

The financial and emotional exposure is not always viable to allow students to completely decide what type of projects they want to pursue in the educational process. However, if educators and curriculum designers make sure that these dimensions are to some degree included in the educational programs, students will have the opportunity to learn what it is like to be a professional, including the responsibility, loneliness and liability 
of newness that accompany new venture creation. There is thus not only a focus on the entrepreneurial process in these types of programs, but also a strong focus on the management oriented- method.

\section{References}

1. A. Sherstneva, Smart Innovation, Systems and Technologies, 139 (2019)

2. A. Sherstneva, Advanced in economics, business and management research, 81 (2019)

3. K. Moberg, H. Barslund Fosse, A. Hoffman, M. Junge, Danish foundation for entrepreneurship, 94 (2015)

4. R. Baron, Entrepreneurship: An evidence-based guide (2012)

5. F. Cunha, J. J. Heckman, Investing in Our Young People, Cambridge University Press, New York (2010)

6. W.B. Gartner, N.M. Carter, Entrepreneurial behaviour and firm organizing processes (2003)

7. J. Heinonen, U. Hytti, Entrepreneurship and Innovation, 11 (2010)

8. L Rosendahl Huber, R. Sloof, C.M. Van Praag, European Economic Review, 72 (2014)

9. K.R. Wentzel, J.E. Brophy, Motivating Students to Learn (2013) 